\title{
Hidratação da magnésia e seu efeito ligante em concretos refratários sem cimento
}

\section{(Magnesia hydration and its binder effect on cement-free refractory castables)}

\author{
T. M. Souzal ${ }^{\text {** }}$ M. A. L. Braulio ${ }^{1}$, P. Bonadia ${ }^{2}$, V. C. Pandolfelli ${ }^{1 * *}$ \\ ${ }^{1}$ Grupo de Engenharia de Microestrutura de Materiais - GEMM, Departamento de Engenharia de Materiais, \\ Universidade Federal de S. Carlos, Rod. Washington Luiz, km 235, C.P. 676, S. Carlos, SP 13565-905 \\ ${ }^{2}$ Magnesita Refratários S.A., Centro de Pesquisas e Desenvolvimento \\ Praça Louis Ensch 240, Contagem, MG \\ *uaitiago@gmail.com,**vicpando@power.ufscar.br
}

\begin{abstract}
Resumo
Apesar da hidratação da magnésia constituir uma dificuldade para o seu uso em concretos refratários, trabalhos recentes indicam que o controle da expansão volumétrica associada a esta reação pode ser utilizado para promover o desenvolvimento de resistência mecânica em concretos sem cimento, resultando em um ligante a base de magnésia. Considerando este aspecto, o objetivo do presente trabalho foi avaliar o potencial do $\mathrm{MgO}$ e da combinação $\mathrm{MgO}-\mathrm{SiO}_{2}$ como agentes ligantes para concretos refratários. Com este propósito utilizou-se três fontes de $\mathrm{MgO}$ distintas, um sínter de magnésia e duas magnésias cáusticas. Para o sistema MgO$\mathrm{SiO}_{2}$, teores distintos de microssílica (1\%-p, $2 \%$-p e 4\%-p) foram adicionados aos concretos a fim de evitar os danos causados pela hidratação da magnésia. Os resultados obtidos destacam que para o sínter de $\mathrm{MgO}$, calcinado acima de $1500{ }^{\circ} \mathrm{C}$, a baixa razão CaO/ $\mathrm{SiO}_{2}$ é um dos pré-requisitos para a redução dos efeitos deletérios associados à hidratação. Para as magnésias cáusticas (calcinadas abaixo de $1200{ }^{\circ} \mathrm{C}$ ) o teor de $\mathrm{SiO}_{2}$ e $\mathrm{CaO}$ livre são fundamentais para determinar o efeito ligante e a integridade física final do produto. Além disto, a adição de microssílica apresentou-se como um mecanismo eficiente para controlar a hidratação de diferentes fontes de $\mathrm{MgO}$, entretanto, teores elevados de microssílica podem resultar em uma redução acentuada da fluidez.

Palavras-chave: hidratação da magnésia, ligante a base de magnésia, concretos refratários.
\end{abstract}

\begin{abstract}
Due to its hydration, the use of fine magnesia in refractory castables is a key concern. Nevertheless, recent studies pointed out that the volume expansion associated with this reaction can be used to develop strength in cement-free castables, resulting in magnesia based binder. Considering this aspect, the objective of the present work was to evaluate the potential of $\mathrm{MgO}$ and $\mathrm{MgO}-\mathrm{SiO}$, as binders for refractory castables. With this purpose, three different sources of magnesia were used, one dead-burned and two caustic ones. For the $\mathrm{MgO}-\mathrm{SiO}_{2}$ system different amounts of fumed silica (1wt.\%, 2wt.\% and 4wt.\%) were added to the castable compositions in order to avoid the damages caused by magnesia hydration. The results attained pointed out that for the sinter calcined above $1500{ }^{\circ} \mathrm{C}$, the low $\mathrm{CaO} / \mathrm{SiO}_{2}$ ratio is one of the important issues to inhibit the deleterious effects associated to the hydration. For the caustic magnesia (calcined below $1200^{\circ} \mathrm{C}$ ) the free $\mathrm{SiO}_{2}$ and $\mathrm{CaO}$ contents are fundamental for the binding potential and final physical integrity of the product. Furthermore, the addition of fumed silica was presented as an efficient mechanism to control the hydration of different $\mathrm{MgO}$ sources; however, high levels of fumed silica can result in a marked castable flow reduction.
\end{abstract}

Keywords: magnesia hydration, magnesia based binder, refractory castables.

\section{INTRODUÇÃ̃O}

Devido ao seu elevado ponto de fusão $\left(2800{ }^{\circ} \mathrm{C}\right)$ e sua boa resistência ao ataque por escórias básicas, o óxido de magnésio éuma das principais matérias-primas para produção de refratários do setor siderúrgico. Em concretos refratários do sistema $\mathrm{Al}_{2} \mathrm{O}_{3}-\mathrm{MgO}$, a reação da magnésia com a alumina (a partir de $1000^{\circ} \mathrm{C}$ ) resulta na formação de espinélio in situ, que possui maior resistência à penetração por escórias que as composições equivalentes contendo espinélio préformado [1]. Entretanto, ao entrar em contato com a água durante a mistura, cura ou secagem dos concretos ou devido à exposição à umidade, o $\mathrm{MgO}$ hidrata-se facilmente, resultando na formação de brucita $\left[\mathrm{Mg}(\mathrm{OH})_{2}\right]$. Este fenômeno é acompanhado por uma expansão volumétrica, devido à diferença de densidade entre a magnésia $\left(\rho_{\mathrm{MgO}}=\right.$ $\left.3,53 \mathrm{~g} / \mathrm{cm}^{3}\right)$ e o produto da reação de hidratação, o hidróxido de magnésio $\left(\rho_{\mathrm{Mg(OH})_{2}}=2,4 \mathrm{~g} / \mathrm{cm}^{3}\right)$. Tal aspecto pode resultar em danos mecânicôs como a formação de trincas ou a completa desintegração do material. Considerando-se os efeitos deletérios causados pela hidratação da magnésia, um grande esforço tem sido dirigido ao desenvolvimento 
de técnicas anti-hidratação a fim de se inibir esta reação e, consequentemente, eliminar ou reduzir os danos associados a ela [2-5]. Por outro lado, uma inovação significativa seria se ao invés de evitar a hidratação do $\mathrm{MgO}$, esta pudesse ser controlada e a precipitação de brucita fosse utilizada como mecanismo de fortalecimento dos concretos.

Um ligante à base de magnésia foi recentemente desenvolvido por meio da otimização do tamanho de partículas de um sínter de $\mathrm{MgO}$ [6]. Partículas mais finas facilitam a acomodação da expansão gerada na reação de hidratação eliminando seus efeitos deletérios. Uma alternativa que também parece apropriada é a adição de microssílica com o intuito de controlar a hidratação da magnésia. O efeito ligante do sistema $\mathrm{MgO}-\mathrm{SiO}_{2}$ foi avaliado, indicando que a magnésia reage com a água e com a microssílica resultando em concretos com boa resistência mecânica à verde [7]. $\mathrm{O}$ desenvolvimento de concretos refratários sem cimento utilizando-se um ligante a base de magnésia proporcionaria grandes impactos tecnológicos e econômicos na indústria. Tecnológicos porque a reação do $\mathrm{CaO}$ (proveniente do cimento) com $\mathrm{Al}_{2} \mathrm{O}_{3}$ e $\mathrm{SiO}_{2}$ resulta na formação de fases de baixo ponto de fusão [tal como anortita $\left(\mathrm{CaAl}_{2} \mathrm{Si}_{2} \mathrm{O}_{8}\right)$ e guelenita $\left(\mathrm{Ca}_{2} \mathrm{Al}_{2} \mathrm{SiO}_{7}\right)$ ] que deterioram as propriedades mecânicas a quente dos concretos [8]. Econômicos porque a magnésia é uma matéria-prima de custo inferior quando comparada ao cimento, que é responsável por uma parcela significativa do custo total dos concretos. Além disto, de acordo com o diagrama de fases para o sistema $\mathrm{Al}_{2} \mathrm{O}_{3}-\mathrm{MgO}-$ $\mathrm{SiO}_{2}$, para composições com alto teor de alumina dentro do triângulo de compatibilidade alumina-espinélio-mulita, em condições de equilíbrio espera-se um concreto constituído pelas fases alumina, espinélio e mulita, com formação de líquido apenas acima de $1578{ }^{\circ} \mathrm{C}$. Considerando esses aspectos, o presente trabalho teve por objetivo avaliar o efeito ligante do $\mathrm{MgO}$ e do sistema $\mathrm{MgO}-\mathrm{SiO}_{2}$ utilizandose fontes de magnésia com reatividade distintas, tais como o sínter de $\mathrm{MgO}$ e magnésias cáusticas. A avaliação do sistema $\mathrm{MgO}-\mathrm{SiO}_{2}$ foi realizada por meio da adição de teores distintos de microssílica (1\%-p, 2\%-p e 4\%-p) a fim de controlar a hidratação da magnésia evitando seus efeitos deletérios. Finalmente foi realizada uma comparação entre concretos ligados pelo sistema $\mathrm{MgO}$ e $\mathrm{MgO}-\mathrm{SiO}_{2}$ e uma composição sem magnésia contendo baixo teor de cimento de aluminato de cálcio.

\section{MATERIAIS E MÉTODOS}

Três fontes de $\mathrm{MgO}$ foram utilizadas para avaliar o potencial da magnésia e do sistema $\mathrm{MgO}-\mathrm{SiO}_{2}$ como ligantes para concretos refratários. Um sínter de $\mathrm{MgO}$ (SM) e duas fontes de magnésia cáustica ( $\mathrm{MC1}$ e $\mathrm{MC} 2)$, com áreas superficiais iguais a $1,05 \mathrm{~m}^{2} / \mathrm{g}, 11,12 \mathrm{~m}^{2} / \mathrm{g}$ e 24,57 $\mathrm{m}^{2} / \mathrm{g}$, respectivamente (Magnesita Refratários S.A., Brasil). A Tabela I apresenta as propriedades físicas e químicas e as composições químicas das fontes de magnésia utilizadas.

O valor da atividade foi determinado por meio da reação de 5,0 g de magnésia com $100 \mathrm{~mL}$ de uma solução
Tabela I - Propriedades físicas e químicas e composição química das fontes de magnésia selecionadas.

[Table I - Physical and chemical properties and chemical composition for selected magnesia sources.]

\begin{tabular}{|c|c|c|c|c|}
\hline \multicolumn{2}{|c|}{ Fonte de $\mathrm{MgO}$} & SM & $\mathrm{MC} 1$ & MC2 \\
\hline \multirow{6}{*}{$\begin{array}{l}\text { Propriedades } \\
\text { físicas e } \\
\text { químicas }\end{array}$} & $\mathrm{AS}\left(\mathrm{m}^{2} / \mathrm{g}\right)$ & 1,05 & 11,12 & 24,57 \\
\hline & $\mathrm{D}_{10}(\mu \mathrm{m})$ & 0,55 & 2,05 & 2,00 \\
\hline & $\mathrm{D}_{50}(\mu \mathrm{m})$ & 7,76 & 20,14 & 16,58 \\
\hline & $\mathrm{D}_{90}(\mu \mathrm{m})$ & 35,48 & 52,19 & 51,09 \\
\hline & $\rho\left(\mathrm{g} / \mathrm{cm}^{3}\right)$ & 3,53 & 3,20 & 3,38 \\
\hline & Atividade (s) & 2207 & 259 & 38 \\
\hline \multirow{7}{*}{$\begin{array}{c}\text { Composição } \\
\text { química (\%- } \\
\text { p) }\end{array}$} & $\mathrm{MgO}$ & 98,17 & 94,73 & 98,38 \\
\hline & $\mathrm{CaO}$ & 0,84 & 0,42 & 0,88 \\
\hline & $\mathrm{SiO}_{2}$ & 0,33 & 1,58 & 0,17 \\
\hline & $\mathrm{Al}_{2} \mathrm{O}_{3}$ & 0,12 & 0,35 & 0,05 \\
\hline & $\mathrm{Fe}_{2} \mathrm{O}_{3}$ & 0,41 & 2,06 & 0,42 \\
\hline & $\mathrm{MnO}$ & 0,13 & 0,86 & 0,10 \\
\hline & $\mathrm{CaO} / \mathrm{SiO}_{2}$ & 2,54 & 0,27 & 5,18 \\
\hline
\end{tabular}

AS: área superficial; $D_{10}, D_{50}$ e $D_{90}$ : tamanho de particulas; $\rho$ : densidade.

$1 \mathrm{~N}$ de ácido acético. A atividade é expressa como o tempo para a completa neutralização do ácido acético e é dada em segundos. Adicionalmente, suspensões aquosas foram preparadas visando-se avaliar as diferenças de hidratação entre as fontes de $\mathrm{MgO}$ e a temperatura de decomposição do $\mathrm{Mg}(\mathrm{OH})_{2}$. A proporção em peso de magnésia/água utilizada foi de 1:2. Primeiramente as suspensões foram agitadas por $5 \mathrm{~h}$ à temperatura ambiente em um misturador de bancada e depois por mais $2 \mathrm{~h}$ a $90{ }^{\circ} \mathrm{C}$, para acelerar o processo de hidratação da magnésia. Em seguida, as amostras foram secas por $24 \mathrm{~h}$ a $110^{\circ} \mathrm{C}$ para remoção da água livre, permitindo-se a determinação do perfil de secagem por meio de análises termogravimétricas, técnica que será detalhada nesta seção.

Composições de concreto refratário vibrado de alta alumina sem cimento e contendo $6 \%$-p de magnésia (magnésia cáustica ou sínter de magnésia, Magnesita Refratários S.A., Brasil), 7\%-p de alumina reativa (CL370, Almatis, EUA) e 0\%-p, 1\%-p, 2\%-p ou 4\%-p de microssílica (971U, Elkem, Noruega) foram utilizadas nos testes. Uma formulação sem magnésia contendo $6 \%$-p de cimento de aluminato de cálcio (Secar 71, Kerneos, França) e 1\%-p de microssílica foi também preparada para comparação com os concretos sem CAC. Aluminas tabulares $(\mathrm{d} \leq 6 \mathrm{~mm}$, Almatis, EUA) constituíram os agregados e a dispersão foi garantida adicionando-se um aditivo dispersante eletroestérico (Basf, Alemanha). A formulação foi planejada considerando-se o modelo de empacotamento de Alfred $(\mathrm{q}=0,26)$ e o teor de água para cada composição foi ajustado de acordo com um alvo de fluidez inicial sob vibração de $80 \%$, visando-se uma moldagem adequada. A Tabela II apresenta as principais características das composições avaliadas e a Tabela III o teor de água utilizado para o processamento dos concretos.

Após moldagem, os concretos foram curados a $50{ }^{\circ} \mathrm{C}$ 
Tabela II - Composições dos concretos refratários estudados.

[Table II - Compositions of the evaluated refractory castables.]

\begin{tabular}{cccccc}
\hline \multirow{2}{*}{ Matérias primas } & \multicolumn{5}{c}{$\%$-peso } \\
\cline { 2 - 6 } & \multicolumn{6}{c}{ Contendo MgO (SM, MC1 ou MC2) } & Sem MgO (6CAC) \\
\cline { 2 - 6 } & $0 \mathrm{MS}$ & $1 \mathrm{MS}$ & $2 \mathrm{MS}$ & $4 \mathrm{MS}$ & $1 \mathrm{MS}$ \\
\hline Alumina tabular (d $\leq 6 \mathrm{~mm})$ & 81 & 80 & 79 & 77 & 80 \\
Alumina reativa (CL370) & 7 & 7 & 7 & 7 & 7 \\
Microssílica (971 U) & 0 & 1 & 2 & 4 & 1 \\
Magnésia (SM, MC1, MC2) & 6 & 6 & 6 & 6 & 0 \\
Cimento de aluminato de cálcio (Secar 71) & 0 & 0 & 0 & 0 & 6 \\
Alumina tabular (d<45 $\mu \mathrm{m})$ & 6 & 6 & 6 & 6 & 6 \\
Dispersante & 0,2 & 0,2 & 0,3 & 0,4 & 0,2 \\
\hline
\end{tabular}

Tabela III - Teor de água adicionado aos concretos refratários estudados.

[Table III - Water content added to the refractory castables.]

\begin{tabular}{ccccc}
\hline \multirow{2}{*}{ Composição o } & \multicolumn{4}{c}{ Teor de água (\%-p) } \\
\cline { 2 - 5 } & $0 \mathrm{MS}$ & $1 \mathrm{MS}$ & $2 \mathrm{MS}$ & $4 \mathrm{MS}$ \\
\hline $\mathrm{SM}$ & 4,0 & 4,1 & 4,1 & 4,2 \\
$\mathrm{MC} 1$ & 5,1 & 5,2 & 5,2 & 5,4 \\
$\mathrm{MC} 2$ & 5,1 & 5,8 & 6,1 & 6,4 \\
6CAC & - & 4,2 & - & - \\
\hline
\end{tabular}

em uma câmara climática (Vöetsch 2020, Alemanha) com umidade relativa de $80 \%$. O processo de cura foi acompanhado ao longo de 7 dias utilizando-se medidas do módulo de Young, porosidade aparente e medidas da perda de água associada à secagem. Para a determinação do perfil de secagem realizou-se o ensaio de termogravimetria, conforme procedimento mencionado a seguir. Para avaliação do módulo de Young, os concretos foram moldados na forma de barras retangulares com dimensões aproximadas de 150 x $25 \times 25 \mathrm{~mm}^{3}$. Após $3 \mathrm{~h}$ de cura, os corpos-de-prova foram cuidadosamente desmoldados e as medidas do módulo elástico foram iniciadas. $\mathrm{O}$ módulo de Young foi avaliado por meio da técnica de ressonância de barras utilizando-se o equipamento Scanelastic (ATCP, Brasil), de acordo com a norma ASTM C 1198-91. O arranjo experimental deste ensaio consiste na excitação da amostra e na detecção de seu espectro de vibração por meio da utilização de transdutores piezoelétricos. A excitação é realizada em uma faixa de freqüências suficiente para obtenção das freqüências naturais de ressonância das barras, e, a partir dos modos normais de vibração calcula-se o módulo de Young, utilizando-se as equações de Pickett, que relacionam o módulo elástico, as frequiências naturais de vibração e as dimensões da amostra [9]. Para freqüência fundamental de flexão das barras o módulo de Young é dado por:

$$
\mathrm{E}=0,9465 \frac{\mathrm{mf}_{\mathrm{f}}^{2}}{\mathrm{~b}} \times \frac{\mathrm{L}^{3}}{\mathrm{t}^{3}} \times \mathrm{T}^{1}
$$

onde E é o módulo de Young (Pa), m a massa (g), b a largura (mm), L o comprimento (mm), t a espessura (mm), $\mathrm{f}_{\mathrm{f}}$ a freqüência fundamental de ressonância da barra em flexão $(\mathrm{Hz})$ e $\mathrm{T}_{1}$ o fator de correção para o modo de flexão fundamental, que considera a espessura finita da barra e a razão de Poisson.

A porosidade aparente das amostras foi avaliada de acordo com a norma ASTM C 830, com querosene como fluido de imersão. Durante a cura, a perda de água associada à secagem foi determinada utilizando-se a equação:

$$
\mathrm{W}_{\text {acumulada }}=100 \times\left(\frac{\mathrm{M}_{0}-\mathrm{M}_{\mathrm{f}}}{\mathrm{M}_{0}}\right)
$$

onde $\mathrm{W}_{\text {acumulada }}(\%-\mathrm{p})$ é perda de água acumulada, $\mathrm{M}_{0}$ a massa da amostra (g) no início da cura e $\mathrm{M}_{\mathrm{f}}$ a massa final (g) após cada intervalo de tempo.

Para os ensaios de termogravimetria, as amostras foram curadas a $50{ }^{\circ} \mathrm{C}$ por $24 \mathrm{~h}$. Os testes foram conduzidos até $800{ }^{\circ} \mathrm{C}$ em um equipamento de análise termogravimétrica [10], com taxa de aquecimento de $10{ }^{\circ} \mathrm{C} / \mathrm{min}$. A perda de massa cumulativa (W) e a velocidade de secagem (dW/dt) foram calculadas conforme as equações abaixo:

$$
\begin{aligned}
& \mathrm{W}(\%)=100 \times\left(\frac{\mathrm{M}_{0}-\mathrm{M}}{\mathrm{M}_{0}-\mathrm{M}_{\mathrm{f}}}\right) \\
& \left(\frac{\mathrm{dW}}{\mathrm{dt}}\right)_{\mathrm{i}}=\left(\frac{\mathrm{W}_{(\mathrm{i}+10)}-\mathrm{W}_{(\mathrm{i}-10)}}{\mathrm{t}_{(\mathrm{i}+10)}-\mathrm{t}_{(\mathrm{i}-10)}}\right)
\end{aligned}
$$

onde $\mathrm{M}_{0}$ é a massa inicial (g), $\mathrm{M}$ a massa instantânea $(\mathrm{g})$ registrada em um tempo $t_{i}(\mathrm{~s})$ e $\mathrm{M}_{\mathrm{f}}$ a massa final da amostra (g). A taxa de secagem é dada em $\% / m i n$.

\section{RESULTADOS E DISCUSSÃO}

\section{A. Avaliação das fontes de $\mathrm{MgO}$ utilizadas}

A Fig. 1a apresenta os resultados de atividade (tempo de neutralização) em função da área superficial para cada uma das fontes de $\mathrm{MgO}$ utilizadas. Quanto menor o tempo 

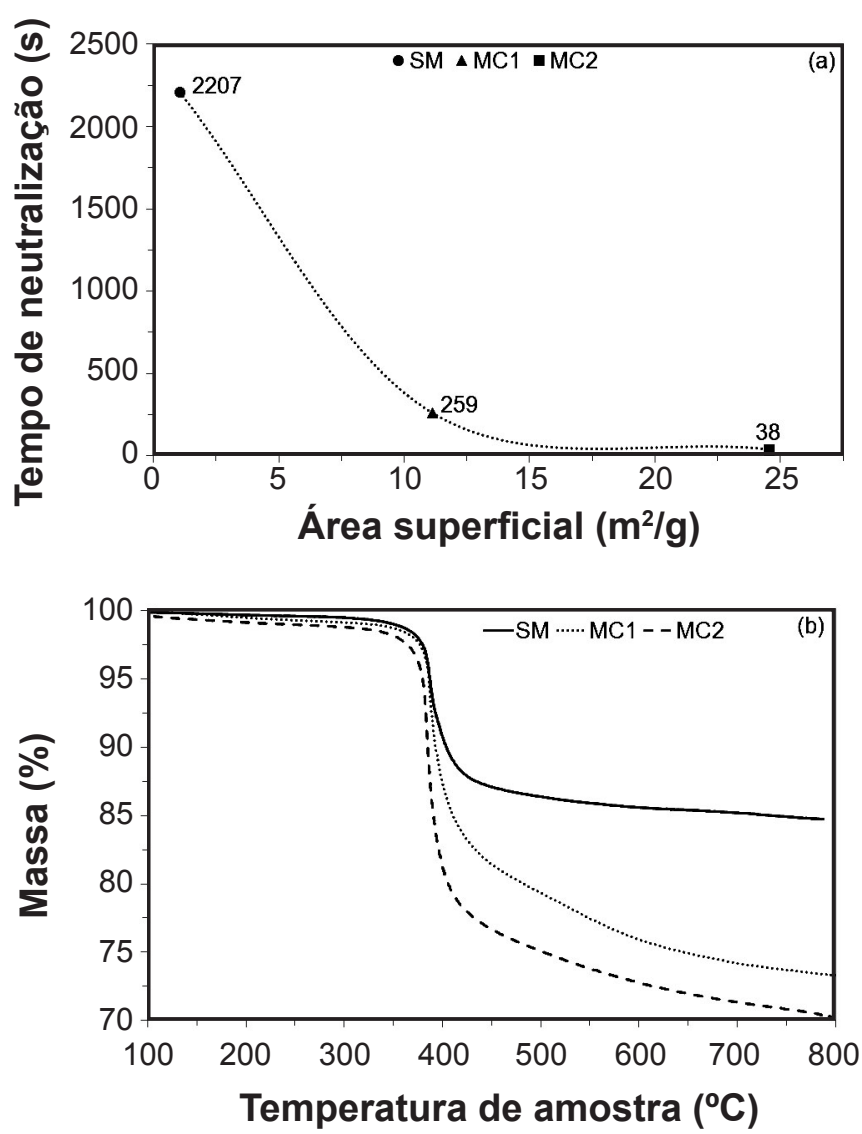

Figura 1: (a) Tempo de neutralização em função da área superficial da fonte de $\mathrm{MgO}$ e (b) perda de massa em função da temperatura para as suspensões de sínter de magnésia (SM) e magnésias cáusticas ( $\mathrm{MC} 1$ e $\mathrm{MC} 2)$.

[Figure 1: (a) Neutralization time as a function of sample's specific surface area and (b) mass loss curve profiles as a function of sample's temperature for dead-burned magnesia (SM) and caustic magnesia (MC1 and MC2) suspensions.]

de neutralização maior é a atividade da fonte de magnésia. A amostra de SM (com menor área superficial) apresenta o maior tempo de neutralização e, portanto, é a fonte de magnésia menos reativa. $\mathrm{O}$ valor da atividade aumenta com o aumento da área superficial, entretanto, a diferença do tempo de neutralização entre fontes de magnésia com elevada área superficial são menos aparentes. Este comportamento indica que a atividade não depende apenas da área superficial, mas também da composição química das partículas, uma vez que o sínter possui menor $\mathrm{D}_{50}$ e $\mathrm{D}_{90}$, mas não apresenta o menor tempo de neutralização. Fontes de magnésia cáustica são obtidas em temperaturas relativamente baixas (850$1000^{\circ} \mathrm{C}$ ) e, conseqüentemente, possuem menor tamanho de cristais. Em temperaturas mais elevadas, como da produção do sínter de $\mathrm{MgO}\left(1800-2000^{\circ} \mathrm{C}\right)$, com o crescimento dos grãos o arranjo atômico torna-se mais regular, ocorrendo uma redução da quantidade de defeitos cristalinos.

Os resultados de perda de massa para as suspensões de $\mathrm{MgO} / \mathrm{H}_{2} \mathrm{O}$ são apresentados na Fig. 1b. Para as fontes de magnésia mais reativas espera-se a formação de uma quantidade maior de brucita, tanto pela maior área superficial quanto da maior densidade de defeitos. Os resultados de perda de massa estão de acordo com esta relação e também indicam que a decomposição do hidróxido de magnésio ocorre na mesma faixa de temperatura (acima de $350{ }^{\circ} \mathrm{C}$ ) independentemente da fonte de $\mathrm{MgO}$ utilizada. Para as condições adotadas na preparação das suspensões verificase que todas as fontes de magnésia apresentam um grau de hidratação significativo, uma vez que de acordo com a relação estequiométrica de decomposição do $\mathrm{Mg}(\mathrm{OH})_{2}$, espera-se uma perda de massa próxima de $30 \%$. No entanto, com base nas diferenças de perda de massa e nos valores de atividade observados pode-se classificar as fontes de magnésia SM, MC1 e MC2 como de reatividade baixa, médio-alta e alta, respectivamente.

\section{B. Efeito ligante do $\mathrm{MgO}$}

A Fig. 2 apresenta os resultados da evolução do módulo elástico, porosidade aparente e perda de água acumulada em função do tempo de cura para os concretos sem microssílica contendo fontes distintas de $\mathrm{MgO}$. Como se verifica na Fig. 2a, no estágio inicial de cura (entre 0 e 12 h) ocorre um aumento do MOE para todos os concretos, que é mais acentuado para as composições contendo magnésia cáustica (MC1 e MC2). Estes resultados indicam que, quando a expansão associada à formação de hidróxido de magnésio não é excessiva e pode ser acomodada na estrutura do concreto, a reação de hidratação do $\mathrm{MgO}$ apresenta um efeito ligante, que dificulta a mobilidade das partículas, aumentando a rigidez dos concretos [11]. Após o período inicial de cura, dois comportamentos distintos são observados (Fig. 2a). Para a composição MC1-0MS, o módulo elástico continua aumentando até o sétimo dia de cura, indicando que a expansão associada à reação de hidratação da magnésia é adequadamente acomodada na estrutura e contribui para o aumento da resistência mecânica do concreto. Por outro lado, observa-se uma redução do MOE antes de $12 \mathrm{~h}$ para o concreto MC2-0MS e após o terceiro dia de cura para a composição SM-0MS, pois as tensões de tração geradas na formação de brucita superam a resistência mecânica do material, resultando no trincamento.

Uma vez que a expansão causada pela formação de brucita é acomodada pela porosidade da estrutura e não ocorre a formação de trincas, esperava-se que o aumento do MOE fosse acompanhado por uma redução da porosidade [12]. No entanto, para as condições de cura adotadas $\left(50{ }^{\circ} \mathrm{C}\right.$ em ambiente com $80 \%$ de umidade relativa), verificou-se um aumento na porosidade para todos concretos entre o primeiro e terceiro dia de cura (Fig. 2b). Este efeito está relacionado à perda de parte da água livre resultado da secagem do concreto (Fig. 2c) e é mais pronunciado quando ocorre a formação de trincas, como para as composições SM-0MS e MC2-0MS (Fig. 2a). Além disto, entre o terceiro e sétimo dia de cura, nota-se um pequeno ganho de massa para os concretos contendo magnésia cáustica, indicando a continuidade da reação de hidratação devido ao contato com o vapor de água. O mesmo 

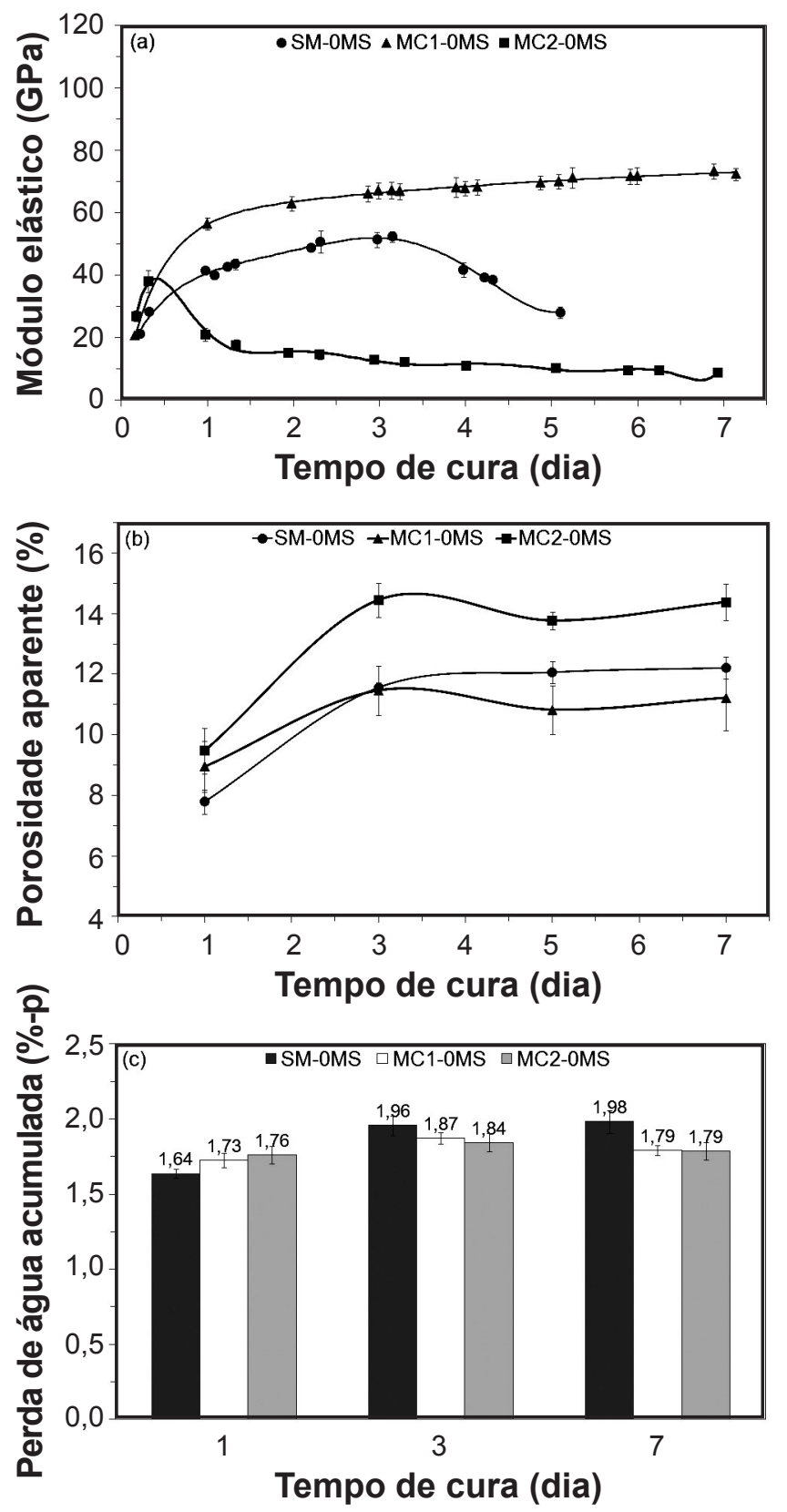

Figura 2: (a) Módulo elástico; (b) porosidade aparente e (c) perda de água acumulada em função do tempo de cura para os concretos contendo diferentes fontes de magnésia (SM, MC1 ou MC2) e sem microssílica (0MS).

[Figure 2: (a) Elastic modulus; (b) apparent porosity and (c) accumulated water loss as a function of curing time for castables with different $\mathrm{MgO}$ sources (SM, MC1 or MC2) and without silica fume (OMS).]

comportamento não foi observado para o sínter (SM) por causa da menor reatividade desta fonte de magnésia. As diferenças observadas entre os concretos não se resumem apenas à fonte de $\mathrm{MgO}$, ou seja, à quantidade de hidróxido de magnésio formado. Como apresentado na Tabela III, para o processamento dos concretos contendo magnésia cáustica utilizou-se um teor de água maior, implicando em um aumento da porosidade e uma redução da resistência mecânica [13]. Por um lado, maiores níveis de porosidade facilitam a acomodação de uma quantidade maior de brucita, porém, concretos com menor resistência mecânica suportam menores deformações sob tração. Apesar de fontes de magnésia mais reativas implicarem na formação de uma quantidade maior de brucita, sua combinação com maiores níveis de porosidade pode favorecer o desenvolvimento de uma rigidez maior durante a cura, como mostrado para o concreto MC1-0MS (Fig. 2a). Estes resultados ressaltam que o desenvolvimento de um ligante magnesiano não está restrito apenas à utilização de fontes de magnésia pouco reativas, mas ao controle da expansão volumétrica associada à hidratação do $\mathrm{MgO}$.

\section{Influência da composição química no efeito ligante do $\mathrm{MgO}$}

Os danos relacionados à formação de brucita em concretos refratários podem ser minimizados por meio da redução do tamanho médio de partículas de $\mathrm{MgO}$ [14]. Pós mais finos possuem maior área superficial, o que resulta em maior hidratação da magnésia, mas ao mesmo tempo facilita a acomodação da expansão gerada, caso suas partículas estejam uniformemente distribuídas no concreto. Tal aspecto foi recentemente explorado para a avaliação do efeito ligante $\mathrm{MgO}$ por meio da moagem de um sínter de magnésia [6]. Apesar das propriedades físicas das fontes de $\mathrm{MgO}$ (como a área superficial e o tamanho médio de partículas) desempenharem um papel importante na acomodação da expansão devido à hidratação do $\mathrm{MgO}$, o concreto contendo $\mathrm{MC} 1$ [fonte de $\mathrm{MgO}$ que apresenta área superficial intermediária, maior tamanho médio de partículas $\left(\mathrm{D}_{50}\right)$ e menor razão $\mathrm{CaO} / \mathrm{SiO}_{2}$ (Tabela I)], foi o único que não apresentou trincas durante a etapa de cura (Fig. 2a). Este resultado indica que a razão $\mathrm{CaO} / \mathrm{SiO}_{2}$ também pode apresentar um efeito importante em evitar danos relacionados à formação de brucita. Durante a calcinação da magnesita $\left(\mathrm{MgCO}_{3}\right)$ para produção do sínter de $\mathrm{MgO}$, as impurezas presentes não permanecem como óxidos livres, mas combinam-se ou reagem com o $\mathrm{MgO}$ formando novas fases, que podem estar distribuídas como filmes nos contornos de grão ou em solução sólida nos cristalitos de magnésia [15]. Sendo assim, as fases formadas a partir das impurezas podem recobrir os cristais de $\mathrm{MgO}$ e gerar uma redução significativa na reatividade destes materiais frente à água. Considerando-se apenas o sistema ternário $\mathrm{MgO}-\mathrm{CaO}-$ $\mathrm{SiO}_{2}$, a razão $\mathrm{CaO} / \mathrm{SiO}_{2}(\mathrm{C} / \mathrm{S})$ controla as fases secundárias que estarão presentes no sínter de magnésia. Como indica a Tabela IV, quanto maior a razão $\mathrm{C} / \mathrm{S}$ mais refratárias serão as fases secundárias formadas. Por outro lado, à medida que ocorre um aumento na razão $\mathrm{CaO} / \mathrm{SiO}_{2}$ nota-se uma tendência maior da presença de $\mathrm{CaO}$ livre. Uma vez que a cálcia apresenta tendência ainda maior de reagir com água e pode gerar uma expansão volumétrica mais pronunciada que a observada na hidratação do $\mathrm{MgO}$, sínteres de magnésia com elevada razão $\mathrm{CaO} / \mathrm{SiO}_{2}$ podem resultar em maiores 
Tabela IV - Compostos de fases sólidas secundárias e temperatura de formação de líquido previstas para o sínter de magnésia considerando-se o sistema $\mathrm{MgO}-\mathrm{CaO}-\mathrm{SiO}_{2}$ [15].

[Table IV - Secondary solid phases and initial liquid formation temperature for dead-burned magnesia in the $\mathrm{MgO}-\mathrm{CaO}-\mathrm{SiO}_{2}$ system [15].]

\begin{tabular}{ccc}
\hline $\mathrm{CaO} / \mathrm{SiO}_{2}$ & $\begin{array}{c}\text { Fases sólidas } \\
\text { secundárias }\end{array}$ & $\begin{array}{c}\text { Temperatura de início } \\
\text { de formação de líquido } \\
\left({ }^{\circ} \mathrm{C}\right)\end{array}$ \\
\hline$<0,93$ & $\mathrm{CMS} \mathrm{e} \mathrm{M}_{2} \mathrm{~S}$ & $\sim 1500$ \\
0,93 & $\mathrm{CMS}_{2}$ & $\sim 1490$ \\
$0,93-1,4$ & $\mathrm{C}_{3} \mathrm{MS}_{2}$ e CMS & $\sim 1490$ \\
1,4 & $\mathrm{C}_{3} \mathrm{MS}_{2}$ & $\sim 1575$ \\
$1,4-1,87$ & $\mathrm{C}_{2} \mathrm{~S} \mathrm{e} \mathrm{C}_{3} \mathrm{MS}_{2}$ & $\sim 1575$ \\
1,87 & $\mathrm{C}_{2} \mathrm{~S}$ & $\sim 1790$ \\
$1,87-2,8$ & $\mathrm{C}_{3} \mathrm{~S} \mathrm{e} \mathrm{C}_{2} \mathrm{~S}$ & $\sim 1790$ \\
2,8 & $\mathrm{C}_{3} \mathrm{~S}$ & $\sim 1850$ \\
$>2,8$ & $\mathrm{C}_{3} \mathrm{~S} \mathrm{e} \mathrm{CaO}$ & 1850 \\
\hline
\end{tabular}

$\mathrm{M}: \mathrm{MgO} ; \mathrm{C}: \mathrm{CaO} ; \mathrm{S}: \mathrm{SiO}_{2}$.

danos durante a cura e a secagem dos concretos.

Uma análise mais detalhada das fases secundárias possíveis para o sínter de magnésia é dada em [16]. De acordo com as combinações de fases sólidas previstas para o sistema $\mathrm{MgO}-\mathrm{CaO}-\mathrm{SiO}_{2}-\mathrm{Fe}_{2} \mathrm{O}_{3}-\mathrm{Al}_{2} \mathrm{O}_{3}$, para a razão molar $\mathrm{CaO} / \mathrm{SiO}_{2}$ menor que 2,0, as impurezas (o óxido de ferro e a alumina) formam uma solução sólida com a magnésia enquanto para razão maior que 2,0 estes óxidos podem reagir parcialmente ou totalmente com o $\mathrm{CaO}$. Para razão $\mathrm{CaO} /$ $\mathrm{SiO}_{2}$ elevada também observa-se a presença de $\mathrm{CaO}$ livre, o que pode resultar em danos ainda maiores nos concretos. Entretanto, uma previsão das fases secundárias baseada na razão $\mathrm{C} / \mathrm{S}$ faz sentido apenas quando a calcinação da magnesita é realizada em temperaturas superiores a 1500 ${ }^{\circ} \mathrm{C}$, como para o sínter de $\mathrm{MgO}$. No caso das fontes de magnésia MC1 e MC2, a temperatura de calcinação (1000 ${ }^{\circ} \mathrm{C}$ ) não é suficiente para que ocorra a reação entre $\mathrm{CaO}$ e $\mathrm{SiO}_{2}$ e, portanto, não observa-se a formação de fases como o $\mathrm{C}_{2} \mathrm{~S}$ e $\mathrm{C}_{3} \mathrm{~S}$ (Tabela IV), que podem afetar a refratariedade do $\mathrm{MgO}$ e recobri-lo com uma camada vítrea reduzindo sua hidratação. Desta forma, os resultados de módulo elástico para as composições contendo MC1 e MC2 apresentados na Fig. 2a devem estar correlacionados à quantidade de $\mathrm{SiO}_{2}$ e $\mathrm{CaO}$ livre presentes nestas fontes de magnésia (Tabela I). De acordo com informações do fornecedor da matériaprima, após a calcinação a $1000{ }^{\circ} \mathrm{C}$, entre as fases cristalinas da magnésia (MC) notam-se partículas finas de sílica que poderiam atuar reduzindo sua velocidade de hidratação de forma similar à atuação da microssílica, já descrita na literatura [3]. Por outro lado, a presença de $\mathrm{CaO}$ livre pode aumentar os danos associados à hidratação, por causa da formação de $\mathrm{Ca}(\mathrm{OH})_{2}$. A magnésia $\mathrm{MCl}$ possui um teor de $\mathrm{CaO}$ livre baixo $\left(0,42 \%\right.$-p) e uma quantidade elevada de $\mathrm{SiO}_{2}$ livre (1,58\%-p), quando comparada à fonte de magnésia MC2 (Tabela I), o que explica o melhor desempenho do concreto
MC1-0MS (Fig. 2a). Considerando-se a composição química das magnésias cáusticas, o desenvolvimento de um ligante magnesiano pode ser favorecido por meio da seleção de fontes de $\mathrm{MgO}$ mais ricas em $\mathrm{SiO}_{2}$ livre e com uma quantidade reduzida de $\mathrm{CaO}$ livre, uma vez que estes fatores contribuem para o controle da expansão gerada durante a hidratação. Além disto, a adição de agentes antihidratantes, como a microssílica, pode ser outro mecanismo eficiente para o controle da expansão, independente da fonte de magnésia.

\section{Efeito ligante do sistema $\mathrm{MgO}-\mathrm{SiO}_{2}$}

Uma das vantagens da adição de microssílica em concretos refratários é a melhoria significativa do empacotamento de partículas, devido ao efeito lubrificante decorrente de sua morfologia esférica e seu pequeno tamanho de partícula que se acomoda nos interstícios disponíveis e contribui para a redução da porosidade [17]. Em concretos contendo magnésia, a microssílica também desempenha a importante função de proteger a fonte de periclásio contra a hidratação e sua combinação com $\mathrm{MgO}$ pode ser utilizada como um ligante para tais sistemas [7].

As Figs. 3 e 4 apresentam os resultados de MOE e porosidade em função do tempo de cura para os concretos com diferentes teores de microssílica. Como indica a Fig. 3a, a adição de 1\%-p de microssílica, em comparação com a formulação sem microssílica (Fig. 2a), resultou em mudanças significativas no módulo de elasticidade dos concretos contendo SM e MC2. Para o concreto SM-1MS, observa-se um aumento rápido do $\mathrm{MOE}$ até o primeiro dia de cura, não ocorrendo a formação de trincas. Ao mesmo tempo, verifica-se uma redução acentuada da porosidade (Figs. 2b e 4a), indicando que um dos fatores responsáveis por este comportamento é a melhoria no empacotamento das partículas. De forma distinta, o valor máximo de rigidez atingido para a composição MC2-1MS permanece praticamente o mesmo, mas nota-se um atraso no início da redução do MOE em comparação com o concreto sem microssílica (Figs. 2a e 3a). Tal efeito é resultante da atuação da microssílica reduzindo a velocidade de hidratação da magnésia [3] e melhorando o empacotamento das partículas (Fig. 4a). Para o concreto MC1-1MS, a adição de microssílica resultou em uma diminuição dos valores de MOE (Figs. 2a e 3a), que pode ser atribuída principalmente à diminuição da quantidade de hidróxido de magnésio formado.

O efeito da adição da microssílica reduzindo a velocidade de hidratação do $\mathrm{MgO}$ pode ser claramente observado por meio dos resultados da análise termogravimétrica para o concreto contendo $\mathrm{MC} 2$, que é a fonte mais reativa avaliada (Fig. 5). A adição de 1\%-p de microssílica resultou em uma redução acentuada na quantidade de $\mathrm{Mg}(\mathrm{OH})_{2}$, uma vez que a área abaixo dos picos entre $350{ }^{\circ} \mathrm{C}$ e $600{ }^{\circ} \mathrm{C}$ é proporcional a quantidade de hidróxidos decompostos. Para os teores de 2\%-p de 4\%-p de microssílica verifica-se uma diminuição adicional da quantidade de brucita, porém menos pronunciada. 

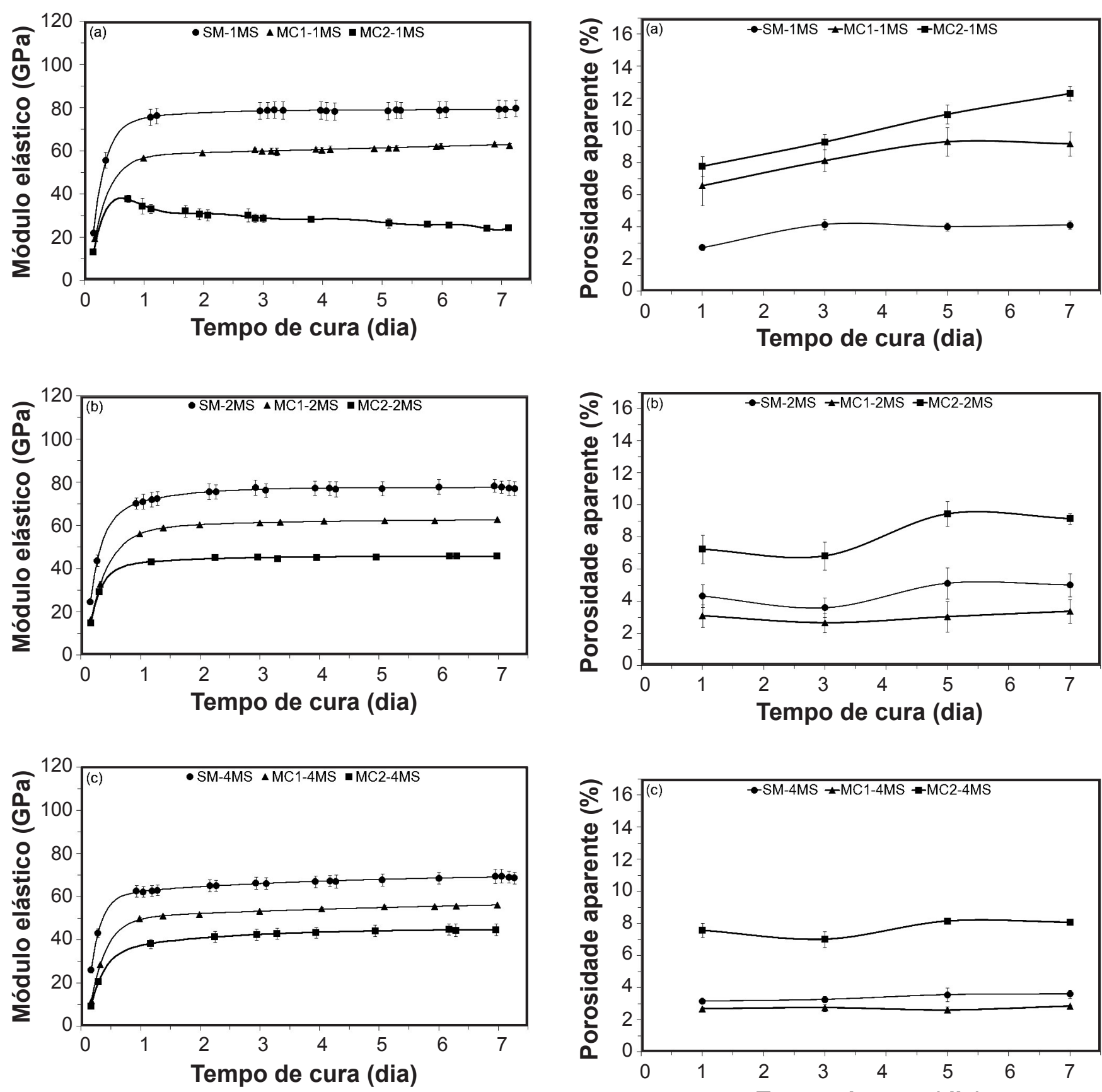

Figura 3: Módulo elástico em função do tempo de cura para os concretos contendo diferentes fontes de magnésia (SM, MC1 ou MC2) e teores de microssílica distintos: a) 1\%-p (1MS); b) 2\%-p (2MS) e c) 4\%-p (4MS).

[Figure 3: Elastic modulus as a function of curing time for castables with different $\mathrm{MgO}$ sources (SM, MC1 or MC2) and silica fume contents: a) 1 wt.\% (1MS); b) 2 wt.\% (2MS) and c) 4 wt.\% (4MS).]

A fase ligante do sistema $\mathrm{MgO}-\mathrm{SiO}_{2}$ consiste no desenvolvimento de uma estrutura essencialmente amorfa e constituída por $\mathrm{MgO}-\mathrm{SiO}_{2}-\mathrm{H}_{2} \mathrm{O}$ [7]. Um estudo adicional mostrou que a quantidade do composto formado é muito pequena e que não pode ser detectada por difração de raios $\mathrm{X}$. Entretanto, por meio da espectroscopia de fotoelétrons excitados por raios X (XPS), que é uma técnica eficiente para

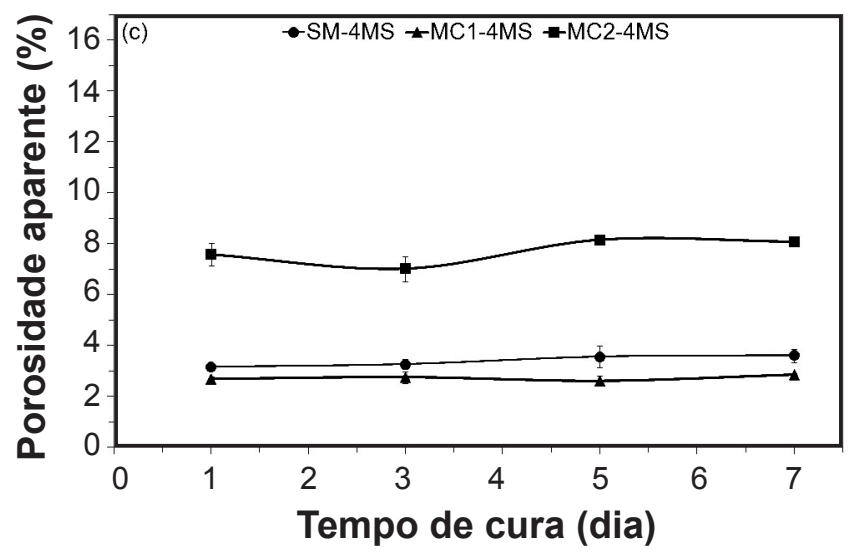

Figura 4: Porosidade aparente em função do tempo de cura para os concretos contendo diferentes fontes de magnésia (SM, MC1 ou MC2) e teores de microssílica distintos: a) 1\%-p (1MS); b) 2\%-p (2MS) e c) 4\%-p (4MS).

[Figure 4: Apparent porosity as a function of curing time for castables with different $\mathrm{MgO}$ sources (SM, MC1 or MC2) and silica fume contents: a) 1 a wt.\% (1MS); b) $2 w t . \%(2 M S)$ and c) $4 w t . \%$ (4MS).]

avaliar a superfície das amostras, verificou-se que a energia de ligação dos elétrons $\mathrm{O}_{1 \mathrm{~s}}, \mathrm{Mg}_{2 \mathrm{p}}$ e $\mathrm{Si}_{2 \mathrm{p}}$ do composto aquoso formado e do talco ( $\left.3 \mathrm{MgO} .4 \mathrm{SiO}_{2} \cdot \mathrm{H}_{2} \mathrm{O}\right)$ são muito próximas. Isto indica que a fase formada para o sistema $\mathrm{MgO}-\mathrm{SiO}_{2}-$ $\mathrm{H}_{2} \mathrm{O}$ possui estrutura semelhante a do talco ou da serpentina $\left(3 \mathrm{MgO} .2 \mathrm{SiO}_{2} \cdot 2 \mathrm{H}_{2} \mathrm{O}\right)$ e que, provavelmente, forma-se na 


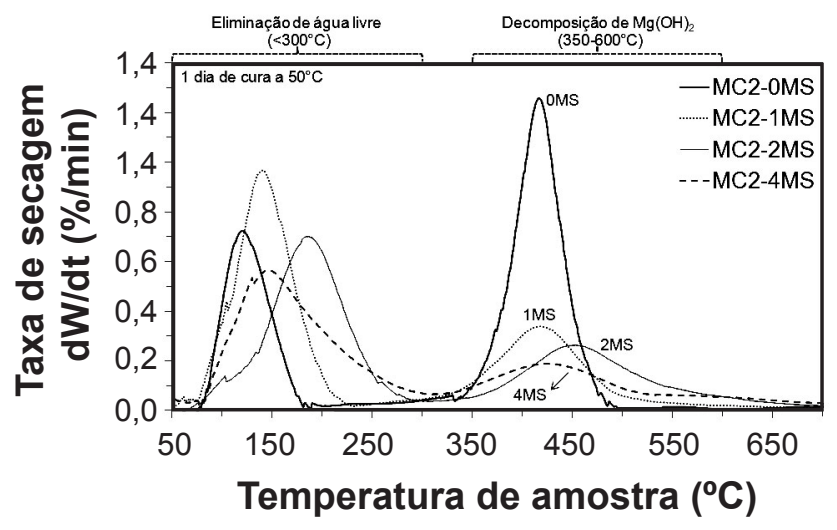

Figura 5: Taxa de secagem em função da temperatura da amostra após 1 dia de cura a $50{ }^{\circ} \mathrm{C}$ para os concretos contendo magnésia cáustica MC2 e teores de microssílica distintos (0MS, 1MS, 2MS ou 4MS).

[Figure 5: Drying rate profiles as a function of sample's temperature after 1 day of curing at $50^{\circ} \mathrm{C}$ for MC2-containing castables with different silica fume contents (0MS, $1 M S, 2 M S$ or $4 M S)$.]

superfície das partículas de magnésia [18]. Apesar da microssílica pura não apresentar sinais de hidratação [19], o pH de concretos refratários magnesianos sem cimento é elevado (>9) [4], sendo suficiente para iniciar a dissolução da microssílica e a formação ácido silicílico [3]. Desta forma, este ácido reage com a brucita, já presente na superfície das partículas de $\mathrm{MgO}$, formando um tipo de silicato de magnésio hidratado que atua reduzindo a velocidade de hidratação da magnésia, uma vez que apresenta baixa solubilidade em água $[3,20]$. Como consequência, a expansão que acompanha a reação de hidratação do $\mathrm{MgO}$ também é minimizada e pode ser acomodada pela porosidade da estrutura. Tais resultados indicam que o teor de microssílica ideal é atingido quando todas as partículas de $\mathrm{MgO}$ são recobertas por um filme de $\mathrm{SiO}_{2}$ e que a quantidade adequada de microssílica será dependente da fonte de magnésia utilizada. Considerandose estes aspectos, teores mais elevados de microssílica (2\%p e 4\%-p) foram adicionados aos concretos e os resultados são apresentados nas Figs. 3b-c e 4b-c. Para o teor de microssílica igual a $2 \%$-p, praticamente não se observam mudanças no MOE dos concretos contendo SM e MC1 (Fig. 2c), enquanto para a composição contendo $\mathrm{MC} 2$ a redução da quantidade de hidróxido de magnésio associada a este teor de microssílica foi suficiente para evitar os efeitos deletérios anteriormente observados (Fig. 2a-b). Aumentando-se o teor de microssílica para 4\%-p nota-se uma pequena diminuição do MOE dos concretos contendo SM e MC1 enquanto para a composição contendo $\mathrm{MC} 2$ o valor do MOE após 7 dias de cura permanece praticamente o mesmo (Fig. 2c-d). O aumento do teor de microssílica pode influenciar tanto a quantidade quanto a estrutura dos silicatos de magnésio hidratados formados. Estudos de síntese hidrotérmica para o sistema magnésia-sílica-água indicam que em temperaturas menores que $200{ }^{\circ} \mathrm{C}$, inicialmente ocorre a cristalização de um silicato de magnésio hidratado semelhante à crisolita $\left(3 \mathrm{MgO} .2 \mathrm{SiO}_{2} \cdot 2 \mathrm{H}_{2} \mathrm{O}\right)$, forma polimórfica da serpentina, sendo que para misturas com maior quantidade de sílica (menor razão $\mathrm{MgO} / \mathrm{SiO}_{2}$ ) observa-se também a formação de fases mais ricas em sílica, similares ao talco $\left(3 \mathrm{MgO} .4 \mathrm{SiO}_{2}\right.$. $\left.\mathrm{H}_{2} \mathrm{O}\right)[21,22]$. Entretanto, para os teores de microssílica avaliados (1 a $4 \%$-p), o efeito ligante continua sendo associado principalmente à hidratação da magnésia, uma vez que a quantidade de silicatos de magnésio hidratado formados é pequena em relação a quantidade de brucita [3]. Uma análise adequada dos resultados de MOE dos sistemas estudados deve considerar principalmente três fatores: 1) a quantidade de $\mathrm{Mg}(\mathrm{OH})_{2}$ formado; 2) a variação na quantidade de agregados de alumina tabular devido a adição de microssílica; e 3) o teor de água utilizado no processamento do concreto. Como indicam os concretos sem microssílica (Fig. 2a), caso não ocorra a formação de trincas, quanto maior a quantidade de brucita maior é a contribuição para o MOE. Por outro lado, com a redução da quantidade de agregados de alumina, devido à adição de microssílica, espera-se uma diminuição do valor do MOE dos concretos, pois policristais de $\alpha-\mathrm{Al}_{2} \mathrm{O}_{3}$ possuem rigidez da ordem de $400 \mathrm{GPa}$ [23] enquanto a sílica fundida e monocristais de quartzo possuem MOE da ordem de 72 $\mathrm{GPa}$ e $95 \mathrm{GPa}$, respectivamente [24]. Além disto, a adição de microssílica reduz a velocidade de hidratação do $\mathrm{MgO}$ e consequentemente a quantidade de hidróxido de magnésio, contribuindo também para a redução do MOE. De acordo com a Tabela III, a adição de microssílica também implicou em um aumento do teor de água utilizado no processamento para garantir a moldagem adequada dos concretos. Em relação à quantidade de água necessária para que a reação de hidratação da magnésia ocorra de forma estequiométrica, um volume adicional de $\mathrm{H}_{2} \mathrm{O}$ não afeta significativamente o grau de hidratação da magnésia [14], mas acarreta em uma diminuição da resistência mecânica dos concretos e, consequentemente, do MOE, uma vez que estas propriedades

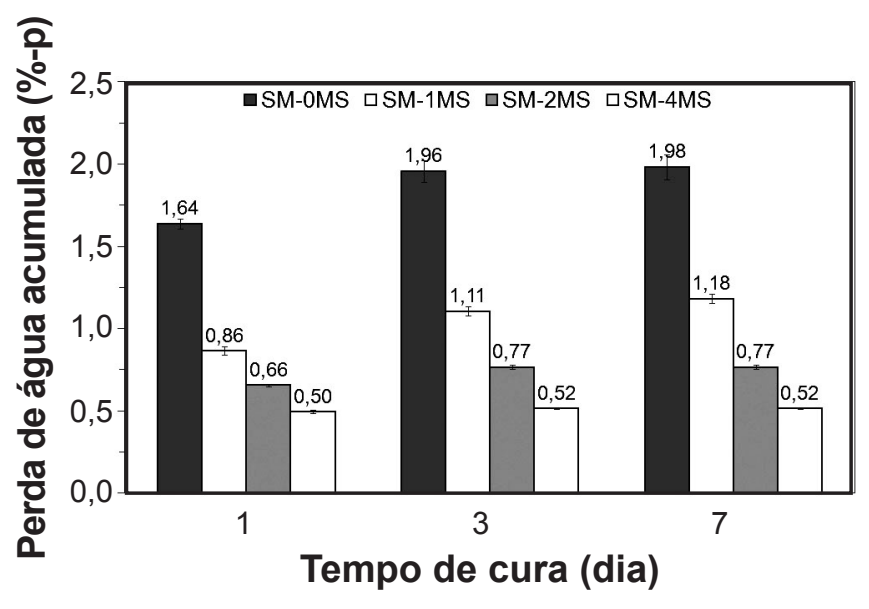

Figura 6: Perda de água acumulada em função do tempo de cura para os concretos contendo sínter de magnésia (SM) e teores distintos de microssílica (0MS, 1MS, 2MS ou 4MS).

[Figure 6: Accumulated water loss as a function of curing time for SM-containing castables with different silica fume contents (OMS, 1MS, $2 M S$ or $4 M S)$.] 
estão correlacionadas [11]. Como discutido anteriormente, para a cura a $50{ }^{\circ} \mathrm{C}$ em ambiente com $80 \%$ de umidade relativa, observa-se entre o primeiro e terceiro dia de cura, um aumento da porosidade devido à secagem do concreto (Fig. 3a). Com a adição de 1\%-p de microssílica este aumento da porosidade é reduzido, e para teores mais elevados (2\%-p e 4\%-p) não é mais observado (Fig. 3a-d). Tal comportamento é um efeito da redução de perda de água durante a secagem, como indicam os resultados para o concreto contendo SM (Fig. 6). O aumento do teor de microssílica implica em uma quantidade maior de silicato de magnésio hidratado formado e, consequentemente, em uma quantidade menor de água livre. Além disto, a adição de microssílica em concretos refratários normalmente é acompanhada por uma redução da permeabilidade [25], acarretando um atraso na secagem dos concretos em relação às temperaturas usuais.

A adição de microssílica é eficiente para o controle da hidratação do $\mathrm{MgO}$ evitando o trincamento dos concretos e a quantidade adequada depende da fonte de magnésia. Os resultados apresentados na Fig. 2 sugerem que, para as fontes $\mathrm{SM}$ e MC2, 1\%-p e 2\%-p de microssílica, respectivamente, são suficientes para reduzir a hidratação da magnésia e evitar os danos anteriormente observados nos concretos. No entanto, a velocidade de hidratação da magnésia aumenta com a temperatura $[26,27] \mathrm{e}$, por isto, os efeitos deletérios são mais acentuados durante a secagem [2]. Sendo assim, para determinação da quantidade de microssílica adequada para cada fonte de $\mathrm{MgO}$ outras propriedades (MOE por exemplo) após a secagem precisam ser consideradas. De forma geral, para as etapas de cura e secagem (baixas temperaturas) do sistema $\mathrm{MgO}-\mathrm{SiO}_{2}$, o efeito ligante continua sendo resultado principalmente da formação de brucita. A microssílica atua melhorando o empacotamento das partículas, o que contribui para aumentar as propriedades mecânicas à verde e auxiliar no controle da expansão gerada, por meio da redução da quantidade de brucita. No entanto, teores elevados de microssílica podem resultar em uma redução acentuada da fluidez e na formação de fases de menor refratariedade, o que constitui uma limitação para o emprego deste componente.

E. Comparação entre os concretos ligados por $\mathrm{MgO}$ ou $\mathrm{MgO}-\mathrm{SiO}_{2}$ com um concreto contendo cimento aluminoso (CAC)

Em relação aos concretos ligados com 6\%-p de cimento de aluminato de cálcio (Fig. 7), as composições ligadas por $\mathrm{MgO}$ e pelo sistema $\mathrm{MgO}-\mathrm{SiO}_{2}$ possuem valores de $\mathrm{MOE}$ significativamente menores (Fig. 2), enquanto os níveis de porosidade são semelhantes ou inferiores (Figs. 3 e 7). Estes resultados deixam claro que o efeito ligante do CAC é superior e que ainda existe a necessidade de melhorias para o emprego do $\mathrm{MgO}$ como ligante. Entretanto, as propriedades mecânicas obtidas para a maioria dos concretos são suficientes para desmoldagem e em alguns casos, possuem o valor mínimo de resistência mecânica requerido pela indústria $(>1 \mathrm{MPa}$ de compressão diametral).

Como um ligante a base de $\mathrm{MgO}$ pode resultar em concretos

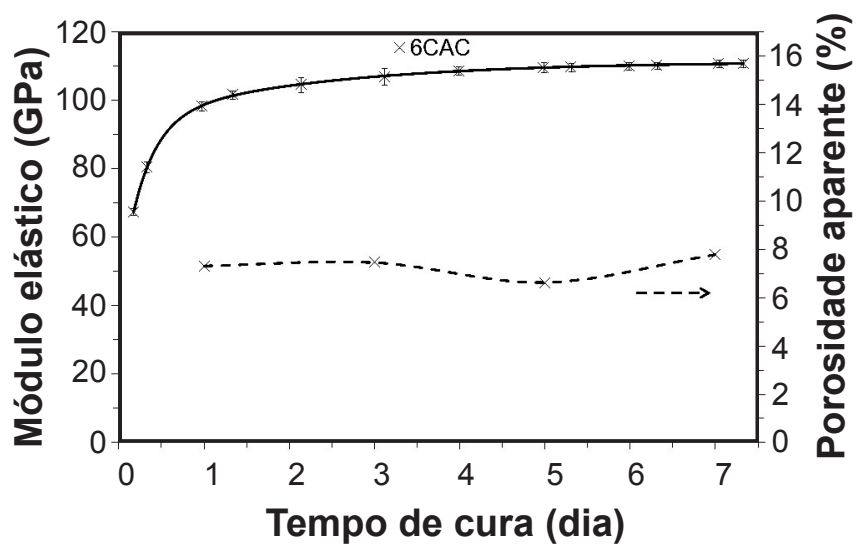

Figura 7: Módulo elástico e porosidade aparente em função do tempo de cura para o concreto contendo 6\%-p de CAC, 1\%-p de microssílica e sem magnésia.

[Figure 7: Elastic modulus and apparent porosity as a function of curing time for the castable containing $6 \mathrm{wt} \%$ of CAC, $1 \mathrm{wt} \%$ of silica fume and without magnesia.]

com elevada refratariedade, maior resistência à corrosão e um custo reduzido, em comparação com as composições ligadas por cimento de aluminato de cácio, este sistema é de grande interesse e deve ser mais explorado. Neste sentido, o sínter de magnésia (SM) e a magnésia cáustica MC1 apresentaram os resultados mais promissores.

\section{CONCLUSÕES}

A utilização do $\mathrm{MgO}$ como ligante está condicionada ao controle da expansão volumétrica associado à hidratação da magnésia e que tanto o sínter de $\mathrm{MgO}(<$ reatividade) quanto as magnésias cáusticas ( $>$ reatividade) apresentam potencial para o desenvolvimento de um ligante magnesiano. Os resultados obtidos também destacam que para o sínter de $\mathrm{MgO}$, calcinado acima de $1500^{\circ} \mathrm{C}$, a baixa razão $\mathrm{CaO} / \mathrm{SiO}_{2}$ é um dos principais pré-requisitos para a redução dos efeitos deletérios associados à hidratação. Para as magnésias cáusticas (calcinadas abaixo de $1200{ }^{\circ} \mathrm{C}$ ) o teor de $\mathrm{SiO}_{2}$ e $\mathrm{CaO}$ livre são fundamentais para determinar o efeito ligante e a integridade física final do produto. Para o sistema $\mathrm{MgO}-\mathrm{SiO}_{2}$ o efeito ligante continua sendo principalmente decorrente da hidratação na magnésia, entretanto a microssílica atua reduzindo a hidratação do $\mathrm{MgO}$ e aumentando o empacotamento das partículas, o que contribui significativamente para a melhoria das propriedades mecânicas à verde. Por outro lado, teores elevados de microssílica causam uma redução da fluidez e podem resultar na formação de fases de baixa refratariedade. Sendo assim, outros aditivos anti-hidratação podem viabilizar a utilização de fontes de magnésia mais reativas como a MC2. Apesar dos concretos ligados por $\mathrm{MgO}$ e $\mathrm{MgO}-\mathrm{SiO}_{2}$ apresentarem propriedades mecânicas inferiores à composição contendo cimento de aluminato de cálcio, algumas das composições cumprem os requisitos mínimos requeridos pela indústria. Fica evidente a necessidade de melhorias, mas o sínter de magnésia (SM) e a magnésia cáustica (MC1) apresentam resultados muito promissores. 


\section{AGRADECIMENTOS}

À Magnesita Refratários S.A., FAPESP e CNPq pelo apoio fornecido ao trabalho.

\section{REFERÊNCIAS}

[1] S. Zhang, W. E. Lee, Spinel-containing refractories, in: C. A. Schacht, "Refractories Handbook", Marcel Dekker Inc., New York, EUA (2004) 215-258.

[2] R. Salomão, L. R. Bittencourt, V. C. Pandolfelli, Ceram. Int. 33 (2007) 803-810.

[3] R. Salomão, V. C. Pandolfelli, Cerâmica 54 (2008) 4348.

[4] R. Salomão, V. C. Pandolfelli, Ceram. Int. 35 (2009) 3117-3124.

[5] A. Yoschida, T. Nemoto, A. Kaneyasu, Proc. UNITECR 2003, Osaka, Japão (2003) 433-436.

[6] R. Salomão, L. R. M. Bittencourt, V. C. Pandolfelli, Interceram 58 (2009) 21-24.

[7] B. Sandberg, T. Mosberg, Ceram. Trans. 4 (1989) 245258.

[8] W. E. Lee, W. Vieira, S. Zhang, K. Ghanbari Ahari, H. Sarpoolaky, C. Parr, Inter. Mat. Ver. 46, 3 (2001) 145-167.

[9] G. Pickett, Proc. Am. Soc. Testing Mater. 45 (1945) 846865.

[10] M. D. M. Innocentini, F. A. Cardoso, M. M. Akyioshi, V. C. Pandolfelli, J. Am. Ceram. Soc. 86, 7 (2003) 1146-48. [11] T. M. Souza, M. A. L. Braulio, P. Bonadia, V. C. Pandolfelli, "Módulo elástico como ferramenta para avaliação da hidratação da magnésia e do processamento de concretos refratários", Cerâmica 58, 347 (2010) 301-312.

[12] P. Lauzon, J. Rigby, C. Oprea, T. Troczynski, G. Oprea, Proc. UNITECR 2003, Osaka, Japão (2003) 54-57.
[13] F. T. Ramal Jr., R. Salomão, V. C. Pandolfelli, Ref. Appl. News 10, 3 (2005) 10-13.

[14] R. Salomão, V. C. Pandolfelli, Proc. UNITECR 2009, Salvador, Brasil (2009) 56.

[15] R. A. Landy, Magnesia Refractories, in: C. A. Schacht, "Refractories Handbook", Marcel Dekker Inc., New York, EUA (2004) 109-149.

[16] J. White, Magnesia-Based Refractories, in: A. M. Alper, "High Temperature Oxides", Academic Press, New York, EUA (1970) 77-141.

[17] B. Myrhe, B. Sandberg, "The use of microsilica in refractory castables", disponível em: www.refractories. elkem.com/dav/b360ef3589.PDF, acesso 10/2010.

[18] N. Li, Y. Wei, B. Myhre, C. Odegard, Proc. UNITECR 1999, Berlin, Alemanha (1999) 97-101.

[19] K. G. Ahari, J. H. Sharp, W. E. Lee, J. Eur. Ceram. Soc. 23 (2003) 3071-3077.

[20] J. Temuujin, K. Okada, K. J. D. Mackenzie, J. Solid State Chem. 138 (1998) 169-177.

[21] G. L. Kalousek, D. Mui, J. Am. Ceram. Soc. 37, 2 (1954) 38-41.

[22] J. Chi-Sun Yang, J. Am. Ceram. Soc. 43, 10 (1960) 542549.

[23] R. G. Munro, J. Am. Ceram. Soc. 80, 8 (1997) 19191928 .

[24] W. C. Oliver, G. M. Pharr, J. Mater. Res. 7, 6 (1992) 1564-1583.

[25] R. D. dos Anjos, M. R. Ismael, F. T. Ramal Jr., V. C. Pandolfelli, Cerâmica 50 (2004) 331-335.

[26] A. Kitamura, K. Onizuka, K. Tanaka, Taikabutsu Overseas 16, 3 (1995) 3-11.

[27] S. D. F Rocha, M. B. Mansur, V. S. T. Ciminelli, J. Chem. Technol. Biotechnol. 79, 8 (2004) 816-821.

(Rec. 03/11/2010, Rev. 25/11/2010, Ac. 31/12/2010) 